\title{
Methodological tools for teaching prospective teachers-philologists to interpret English poetic texts
}

\author{
N.V. Dronyakina ${ }^{1 *}$, and A.O. Pirozhkova ${ }^{2}$ \\ ${ }^{1}$ V.I. Vernadsky Crimean Federal University, Simferopol, Russia \\ ${ }^{2}$ V.I. Vernadsky Crimean Federal University, Simferopol, Russia
}

\begin{abstract}
The article deals with the results of the work with graduate students of philology. The study provides the methodological tools for interpreting the texts in relation to modern interpretative tendencies. In the context of our study a literary text is a model of reality representing the real world - its material and ideal components. The reconstruction of such components requires the use of certain methodology and contributes to the perception of the world picture of a nation. The research develops a typology of English poetic texts based on the principle of interpretativeness. The article provides methodological tools for acquainting students of philological department with these strategies and tactics. The poetic text interpretation in cognitive poetics was made by four-year students of the philological orientation of training. The study was grounded on a competence-based approach in the training of prospective philologists.
\end{abstract}

\section{A problem statement}

Training a competent philologist depends on a large number of factors, which includes teaching based on competence and systematic approaches being grounded on the scientific and systematic principles. Among the competencies distinguished in the process of training the prospective philologists, there are both general professional and professional ones. The ability to work with a poetic text, the formation of translation skills of non-fiction texts is a necessary requirement for a competent philologist, a specialist in the field of foreign philology.

\subsection{The objective of the work}

Questions of competence readiness of future philologists were dealt with by G. Garrard, E. Zhindeeva, V. Zaritskaya, E. Lagay, L. Morya, T. Nikolaeva, N. Plekhanova [1-5].

\footnotetext{
*Corresponding author: alyona.pirozhkov@mail.ru
} 
Various approaches used in the training of future philologists were considered by S. Zolotareva, E. Kuzmina, A.O. Pirozhkova, E.V. Ponomareva, G.A. Solopina, T. Tabachenko, L. Shotskaya [6-9].

English poetry, especially of the XX-XXI centuries, is a conglomerate of various literary movements and schools that differ from each other both in the pictorial way of displaying the human world and in the nature of understanding the surrounding reality and its reproduction in poetic texts.

The methods of linguistic analysis and the theory of interpretation of poetic texts, developed by traditional linguistics, turn out to be insufficient for an adequate interpretation of the content and meaning of poetic texts of the XX-XXI centuries, in which the poetic text loses the lyrical subject, and later the author himself $[10,11]$. In the texts of this period, preference is given to silence, omission of words. Prospective philologists study the features of poetic texts mentioned above in the course of literary criticism, stylistics of the English language, however, the time allocated for the study of modern poetic texts is not enough. In this regard, the relevance of our research is determined, which consists in finding methods and techniques for teaching the interpretation strategies of poetic texts in the courses in English literature, stylistics of the English language, theory and practice of translation.

Changes in poetic thinking were reflected in various kinds of textual anomalies, resulting in excessive complexity in the manifestation of the content and meaning of the postmodern poetic text. The solution to this problem becomes possible due to the emergence of a new paradigm of linguistic knowledge for the second half of the twentieth century - cognitive linguistics. The focus of the new field of knowledge is the combination of language and thinking. Cognitology in general and cognitive poetics, in particular, have developed a methodological apparatus suitable for analyzing poetic speech and interpreting the multidimensional structure of a poetic text and its units due to a new understanding of the nature of linguistic phenomena and the way they are understood by humans [12-20]. Unfortunately, as the separate discipline cognitive linguistics is not taught in educational institutions being briefly discussed in the course of general linguistics or special courses in linguistics. Nevertheless, the teaching of basic philological disciplines is built in the mainstream of this direction of scientific knowledge.

The text space of English poetry is a semiotic fusion of the cultures of English-speaking countries. The study of the text as a text space involves the interpretation of its meaning and meaning, taking into consideration the micro- and macrostructure, i.e., internal and extratextual connections, extralinguistic and intralinguistic contexts.

The core of the poetic world is a system of different types and types of verbal poetic images. The presence of various types of implicates, types of information (content-factual, content-conceptual and content-subtext) in a poetic text enables to distinguish varieties of poetic texts on the principle of interpretability and develop strategies and tactics for their explanation.

The purpose of the study is to develop strategies for the interpretation of the English poetic text for prospective teachers-philologists to understand the specific features of the poetic creativity of poets in different literary and stylistic periods of their activity.

The object of the study is the interpretation of English poetic texts, and the subject is the strategies and tactics of interpretation of English poetic texts of the XX-XXI centuries, developed for prospective philologists.

The published corpus of American poetry of the XX-XXI centuries, having an open access in the Internet, served as illustrative material for the study.

The scientific novelty of the research lies in the development of strategies and tactics for the interpretation of English poetic texts, which are the key to the interpretation of English poetry, contributing to the deepening of the theory of implicitness and methods of 
interpretation of the English poetic text. For the first time, the distribution of English poetic texts according to the principle of interpretability was carried out to explain to students of philological specialties the creative mechanisms of artistic creativity and the complexity of revealing various types of information

\section{Results of the research}

Poetic texts are a reproduction of the development of poetic thinking and artistic consciousness of poets relating to certain literary trends and schools in different historical and cultural epochs of mankind. Each specific period of poetic creativity of the national community has its own characteristic features and specificity of the figurative expression of the surrounding reality and possible worlds. The verbal poetic image is a means of a special organization of the verbal texture of a poetic text, which embodies various types of the ethnos' objectified knowledge about the world. The verbal poetic image may be expressed by a word, a word-combination, a sentence and even a whole text.

In the process of working with texts, the students were informed that in the theory of text interpretation, it is generally accepted that the text has more than one correct meaning and does not admit only one correct interpretation. The poetic text is usually based on indirect characterization, that is implicit description of different aspects of the things, the lyrical hero, etc. Thus, it presupposes multiple interpretations. Traditionally, interpretation means a cognitive procedure for revealing the content of concepts or the meaning of formal elements by means of their application to a particular subject area, as well as the result of this procedure.

Turning to the question of the relevance of one or another philological interpretation of a literary text, it should be noted that the problem of authentic interpretation of a literary work cannot be resolved due to the previously explicated features of literary discourse. However, this does not imply its elimination from the range of problems of a particular paradigm. Moreover, the problem under solution within the framework of a specific literary trend has a positive feature, consisting in the philologists' intention to cover all literary phenomena.

For effective work, students were familiarized with various types of poetic texts, distinguished according to the principle of interpretativeness: simple, complex and complicated.

We consider simple poetic texts to be those in which information is expressed in an explicit or explicit-implicit way. Such information optimizes the information balance of the text and the reader, since it is easier to perceive, does not require reader's different kinds of background information, is based on the experienced knowledge of the addressees, their understanding of the phenomena of reality.

A simple poetic text can contain explicit-implicit information, which is expressed in "dead" or simple types of metaphor (somatic, odor, etc.), simile, epithets, the meaning of which is determined by the lexico-syntactic context and does not require special efforts in deciphering the message. For example, in the verbal poetic image "jelly-hearted" the human heart is compared to jelly. The conceptual implications of the nominative unit "jelly" are soft, shaky, easy to destroy. The generalization of the content of nominative units "jelly" in relation to the lexical unit "heart", which explicates solid matter, suggests that the conceptual metaphor of the verbal poetic image "jelly-hearted" is "a human is sensitivity, softness". However, the basis, for example, of the verbal poetic image "a brain of jelly", in which the mental abilities of a person are also comprehended through the verbal image "jelly", is the conceptual metaphor "human being is stupidity, silence".

Those poetic texts containing proper names, verbal image-symbols that slow down, complicate understanding of the text are considered complex. Students were given the task 
of giving examples of poetic texts containing names and verbal image-symbols. Based on the results of the work, the students provided the following information.

1. Poetic texts containing names. For example, the poem by L. Hughes "A Black Pierrot" contains a verbal poetic image with a proper name: "I am a black Pierrot". In the example under consideration, the name Pierrot activates in the consciousness knowledge about the character of the French folk fair theater, Pierrot (comes from the French "Pierrot", a diminutive of the name "Pierre"). This character appeared in the middle of the 17th century.

The role of Pierrot was played without a mask, with a flour-powdered face. The performer wore a wide peasant shirt. Pierrot's character is dominated by the traits of a sad lover, an unsuccessful rival of Harlequin. So, Pierrot's opposition to Harlequin is obvious (failure - luck, sadness - joy).

The analysis of dictionary definitions, encyclopedic and reference sources enabled to reveal the conceptual implications of antonomasia expressed by the lexical unit "Pierrot": sadness, failure, suffering, weakness, alienation, unhappiness. The implications mentioned above are the constituents of the concept "sorrow" / "sadness". In the verbal poetic image under consideration, the nominative unit Pierrot has an attributive feature being combined with the lexical unit black, explicating that the character belongs to the race of black people, opposes him as a representative of this race to the race of white people represented by Harlequin, who is the favorite of fate, the community. So, the basis of the verbal poetic image "I am a black Pierrot" is the conceptual scheme of a man (black) is suffering, sorrow, alienation. The implicit sense of a dark-skinned person is reconstructed through the conceptual image of a theatrical character, who is white-skinned, powdered with flour. The conducted semantic and conceptual analysis of the verbal poetic image under consideration made it possible to reveal the ethnocultural meaning - a black man is weak, suppressed and oppressed in American society.

2. Poetic texts containing verbal image-symbols. The verbal poetic image "Now / milkweed and blackberries are keepers of the cornfield" (Yu. Komunyakaa "The Way the Cards Fall") implicitly expresses the equality of the black ethnic group and the white people in the American community. The phytonym milkweed is a metaphor for the white man, since the morpheme milk has a semantic component "white" in its inner form. In turn, the phytonym blackberry is a metaphor for a dark-skinned person due to the presence in its structure of the color component "dark". Consequently, the lexical unit cornfield may be defined as a parabolic image of the United States as a multinational country, expressed through the image of a field - an open space, a place of battle with nature, a place where various wild plants and shrubs grow.

Complicated poetic texts may be defined as those which contain intertext, allusion, or are built on the convergence of various stylistic devices. Complicated poetic texts are characterized by the presence of deep implicatives that require the use of a whole range of methods for processing this kind of information.

Let's consider an example of a poetic text complicated by the presence of an allusion in it. So, in the lines of the poem by G. Brooks "Still do i keep my look, my identity": "No other stock / That is irrevocable, perpetual / And its to keep. In castle or in shack. / With rags or robes. Through good, nothing, or ill" the unity of the African American ethnos in a foreign (American) society is implicitly expressed. Devotion to one's traditions became the key to preserving ethnic identity and adapting to new conditions of life, which is verbalized by the nominative unit "No other stock / That is irrevocable, perpetual / And its to keep. Poetic line In castle or in shack. / With rags or robes. Through good, nothing, or ill is an allusion to the vow at a wedding ceremonie (Cf. I promise this day / I make you mine / To worship you / Respect you / Keep you in smiles / Never in tears / Support you / And be 
there / In bad and good / Hug you / And give you peace / To respect you / To love you / Always.)".

The specificity of a poetic text lies in the fact that, by their nature, its units assume a plurality and contradiction of possible interpretations, which results in an ambiguous reading of the entire work. The successful reconstruction of the meaning of the text depends on what strategies and tactics are used for its interpretation, that is, how the model of its interpretation is built. Let us assume that an adequate interpretation of its meaning presupposes, first of all, the interpretation of the system of verbal poetic images.

1. The strategy of reconstruction of the imagery world of a poetic text involves the use of a conceptual analysis of each verbal poetic image.

Tactics 1. Reconstruction of conceptual metaphors, conceptual implications of each verbal poetic image.

Tactics 2. Interpretation of the content of a verbal poetic image.

In verbal poetic images "black pudding", "dark meat", "brown bread", "nursing the tough skins of figs" colour terms black, dark, brown, the tough skins of figs actualize the negative meaning of unattractiveness, low grade or low-quality production as semantic components of the rethought universal gastronyms pudding (traditionally light), meat (a shade of color indicates the quality of the product), bread (color corresponds to the sort and quality), figs (skin wrinkled by nature).

The verbal poetic images mentioned above are based on conceptual metaphors: a darkskinned man is unattractive.

2. Strategy of navigation of the text space. Verbal poetic images are components of the text space, constructed by the cooperative efforts of the author, text and reader. This strategy requires the reconstruction of cognitive operations and procedures underlying the formation of verbal poetic images. Such linguistic processing of the text contributes to a deeper penetration into the content of the poetic text and explication of the idiostyle features of the poet.

Students were offered to analyze a piece of African-American poetic text. In the verbal poetic image "They had never had one in the house before. / The strangeness of it all. Like unleashing / A lion, really. Poised / To pounce. A puma. A panther. A black / Bear" (G. Brooks) the nominative unit They had never had one in the house before explicates a black man-slave (or servant), who is identified with wild animals-predators both in character and in the color of their skin, which is expressed by the lexical units a puma, a panther, a black bear. The nominative units a lion, a puma, a panther, a black bear are verbal image-symbols of courage, strength, courage and rebelliousness.

The analogy drawn between a dark-skinned person and a wild animal carries a positive connotation, since captivity prompts either a person or an animal to decisiveness, selfdefense and struggle. The verbal poetic image mentioned above in which a dark-skinned person is comprehended through specific images of wild animals, the semantic components of which are intertwined in the nodes "color" and "strength" (spirit and body), are formed by the linguo-cognitive procedure of specialization - the author used the name of an animal of a concrete kind.

The strategy of interpretation of the meaning of the text provides for the use of thesaurus analysis to explain the methods and means of encoding implicit information. The choice of cultural code depends on the era in which the text was created; literary movement (romanticism, realism, modernism, postmodernism); genre of poetic text (for example, blues, jazz).

The example of a genre poetic text (African-American jazz poetry), complicated by the convergence of various stylistic devices, was considered (S.A. Brown "Ma Rainey"):

I talked to a fellow, an 'the fellow say,

"She jes 'catch hold of us, somekindaway". 
She sang Backwater Blues one day:

- "it rained fo» days an 'de skies was dark as night,

Trouble raken place in de lowlands at night.

Thundered an 'lightened an' the storm begin to roll

Thousan's of people is not got no place to go.

Den i went an 'stood upon some high ol' lonesome hill,

An 'looked down on the place where i used to live".

In the fragment under consideration, the alternation of the capitalized paranthetic construction is used to break the general rhythm of the text and to highlight the rhythmic segment with the help of a graphic means, similar to the explosive beats of a big drum. This variation in rhythm imitates the improvisation of a jazz style.

In the course of the lesson, it was reported that American literature is represented by ethnic poetry: Native American, African American, Mexican, and the like. The interpretation of such texts requires, first of all, the involvement of encyclopedic knowledge on the history of an ethnos, its culture, religious beliefs, cultural values, stereotyped ideas, social status, and the like. This background knowledge contributed to the reconstruction of cultural meanings scattered throughout the poetic text.

In the verbal poetic image "animals come in all colors. dark meat will roast as fast as whi-te meat especially in the unitedstates of america's new self-cleaning ovens" (H. Madhubuti "Malcolm spoke / who listened?") given to the students for linguistic analysis the USA is interpreted as a microwave oven capable of self-cleaning (the unitedstates of america's new self -cleaning ovens), that is, it is capable of ridding itself of everything unnecessary, useless, of self-healing as an organism of any living being. The metaphor "The animals come in all colors" expresses US multinationalism. The lexical units "dark meat", "whi-te meat" are color epithets and gastronomic metaphors for black people and white people, respectively. The nominative unit "dark meat will roast as fast as whi-te meat especially in the unitedstates of america's new self-cleaning ovens" expresses the physical identity of the feuding races, but not social equality in society.

\section{Conclusions}

Summing up the results mentioned above, we draw attention to the need to apply a competence-based approach in the training of prospective philologists. Taking into consideration the requirements to the content of the professional competencies given in the educational standards, the philologist should be able to work with texts in different aspects, whether it relates to prose or poetry. These competencies also include the skills of translating literary texts.

Thus, working with graduate students, we came to conclusion that translation and analysis of English poetry of the XX-XXI centuries is a rather difficult work in view of the presence of a large number of trends and schools during this period, as well as in connection with the omission of words made in the texts under consideration. The research was based on the principles of cognitive poetics which represents a new way of thinking in linguistics and literature and involves the application of the methodological tools and theory to the literary text interpretation. This new branch of philology studies the strategies and processes that underlie the poetic text, its formation, interpretation and mental structures represented in it. New methodological approaches to the text interpretation regard the literary text as a multifaceted phenomenon. The students' interpretative work presupposes the step-by-step analysis of the text being able to determine not only the literal meaning of the text fragment but also to reveal the implicit information, define the verbal means of its expression. The methodological techniques represented in this article are aimed at developing in the prospective teacher-philologist the ability to penetrate into the 
deep essence of a literary work, to find the sources of aesthetic, educational, emotional impact on the reader in the text. The special formal organization of a literary work requires a student's active interpretive effort in the process of its reception. The author not only conveys an idea to the reader, but creates a specific formal construction that must be identified in the course of a thorough analysis of figurative / connotative structures. In this regard, the literary text is a suggestive form that provokes literary interpretation. The effectiveness of text interpretation depends on a proper application of methodological tools.

When interpreting English poetic texts of the period under review, it is important to apply strategies and tactics, as well as methods of interpreting English poetic texts based on knowledge of the history of the creation of a lyric work, the context in which it functioned. In the process of analyzing a lyric work, it is important to be able to identify simple, complex and complicated poetic texts and highlight the verbal poetic image in the work under analysis.

This study was carried out in connection with the cognitive and discursive direction, namely, cognitive poetics, taking into account the methodological training of students, and also has a practical orientation, can be used at practical lessons in a foreign language, pedagogy, lexicology and stylistics, as well as at the lessons of extracurricular activities.

\section{References}

1. G. Garrard, Problems and prospects in ecocritical pedagogy, Environmental Education Research, 16(2), 233-245 (2010)

2. E.A. Zhindeeva, Improving the methodological competence of a teacher-philologist as a basis for the preparation of a modern dictionary, International Journal of Experimental Education, 10, 53-54 (2012)

3. V.G. Zaritskaya, Theoretical and methodological aspects of the formation of linguistic and cultural competence in the system of professional training of teachers of philology, Donetsk readings 2018: education, science, innovation, culture and challenges of our time, 29-32 (2018)

4. N.A. Plekhanova, Quality management of professional training of bachelorphilologists, Education in the modern world: strategic initiatives, 359-363 (2017)

5. S.A. Zolotareva, Language education in the magistracy as a way of training philologists of a wide profile, Humanization of innovative education in modern conditions: prospects and achievements, 411-416 (2009)

6. E.O. Kuzmina, A Systematic approach to teaching the Russian language and a methodological system of speech development of students of philology, Components of the quality of teaching students in a humanitarian university, 68-72 (2013)

7. A.O. Pirozhkova, Ye.V. Ponomareva, G.A. Solopina, The formation of professional competences of future philologists in distance education, Advances in Social Science, Education and Humanities Research, 437, 822-827 (2020)

8. T.S. Tabachenko, Optimization of professional training of students of philology by the methodology of teaching the Russian language on the basis of the process-cognitive approach, Archivos, 39, 438 (2007)

9. Yu. Obidina, Philosophy and methodology of science, 235 (2017)

10. V. Pivnenko, Problems of modern pedagogical education, Cognitive operations of grammaticalization in speech activity, 55(3), 164-170 (2017) 
11. M. Mahlberg, P. Stockwell, Johan de Joode, M. Brook O'Donnell, CLiC Dickens: Novel uses of concordances for the integration of corpus stylistics and cognitive poetics, Corpora, 11(3), 433-463 (2016)

12. A.V. Kharkhurin, Cognitive poetry: theoretical framework for the application of cognitive psychology techniques to poetic text, Creativity: Theories-Research-Applications, 3(1), 57-81 (2016)

13. N. Atamanova, Poetic sound picture of the world as a way of expressing the sound space of a literary text (on the example of a poetic idiolect of the XIX-XX centuries), Privolzhsky Scientific Bulletin, 9(49), 50-53 (2015)

14. M. Sokolova, Comparison of approaches to the study of stable poetic images, Scientific Notes of Petrozavodsk State University, 1(178), 90-96 (2019)

15. R. Mansurov, Text interpretation as a scientific activity, Journal for General Philosophy of Science, 45, 45-58 (2014)

16. R. Mansurov, The role of foregrounding in interpretation of subtextual and conceptual information in a fictional text, Bulletin of Science and Practice, 6(4), 523$526(2020)$

17. E.A. Ogneva, Literary text interpretation, International Journal of Applied and Fundamental Research, 2, 129 (2015)

18. G.R. Sobirova, Theoretical concept of text and literary text, The Problems of Pedagogy, 1(40), 38-39 (2019)

19. L.G. Romanova, The problem of stylistic overload in translation of English fiction texts into Russian, Russian Linguistic Bulletin, 4(24), 129-131 (2020) 